P. ПИКВЕР, Э. СУУРМАА, А. СЮГИС,

А. ТАММИК, Э. ЛИППМАА

\title{
СПЕКТРОМЕТР ИОННОГО ЦИКЛОТРОННОГО РЕЗОНАНСА С ФУРЬЕ-ПРЕОБРАЗОВАНИЕМ
}

\section{1. Введение}

Спектроскопия ионного циклотронного резонанса (ИЦР) находит все более широкое применение в химии и физике $\left[{ }^{1-4}\right]$. Первыми использовали метод ИЦР в масс-спектрометрии Х. Соммер и др. в 1950 г. $\left[{ }^{5}\right]$ и назвали свой прибор омегатроном. Интерес к методу ИЦР возрос во второй половине 60-х годов в связи с возможностями его применения для исследования ионно-молекулярных реакций [ $\left.{ }^{6}\right]$. В 1970 г. Р. Т. Мак-Айвер первым применил т. н. ячейку удерживания ионов [ $\left.{ }^{7}\right]$ и тем самым положил начало бурному развитию метода и широкому применению его для исследования ионно-молекулярных реакций. Сочетание ИЦР спектрометра с мини-ЭВМ дало возможность разделить во времени возбуждение от регистрации ионов, применить фурье-преобразование и отказаться от порогового генератора $\left[{ }^{8}\right]$. В частности, М. Б. Комизароу и А. Г. Маршалл продемонстрировали в 1975 г. $\left[{ }^{9}\right]$, что метод ИЦР в сочетании с фурье-преобразованием открывает возможности к построению масс-спектрометра большой разрешающей силы по массам. В 1978 г. Р. Т. Мак-Айвер показал $\left[{ }^{10}\right]$, что применение широкополосного моста позволяет отказаться от сканирования магнитного поля в пользу развертки частоты. Спектрометр ИЦР с фурье-преобразованием на основе магнита со сверхпроводящим соленоидом $\left(B^{\prime}=4,7 \mathrm{~T}\right)$, построенный $M$. Аллеманом и др. в 1980 г. [ $\left.{ }^{11}\right]$, обладает сверхвысоким разрешением $10^{7}$ для иона 18 , которое недоступно другим методам масс-спектрометрии.

Во второй половине 1980 г. нами завершено конструирование II создание спектрометра ИЦР с фурье-преобразованием [ $\left.{ }^{12}\right]$, который позволяет работать и в режиме частотного сканирования. Спектрометр состоит из четырех основных частей: электромагнита с питанием, вакуумной системы, ячейки с электронной аппаратурой и мини-ЭВМ.

Электромагнит с диаметром полюсов 200 мм и зазором 70 мм имеет максимальную магнитную идукцию 0,8 Т. Питание магнита стабилизировано только по току с точностью $10^{-6}$.

\section{2. Вакуумная система}

Вакуумная система (рис. 1) располагается на тележке, установленной на рельсах. Она состоит из основной вакуумной системы и вспомогательной для дегазирования исследуемых веществ. Кубическая односекционная ячейка (1) находится между полюсами электромагнита в основной системе, которая откачивается двумя вакуумными насосами. Турбомолекулярный насос ТМН-200 (2) (скорость откачки 200 л/с) отключается от системы вентилем ДУ-100 (3), а магниторазрядный насос «Vacion-30» фирмы «Varian» (4) (30 л/с) - вентилем ДУ-60 (5). 


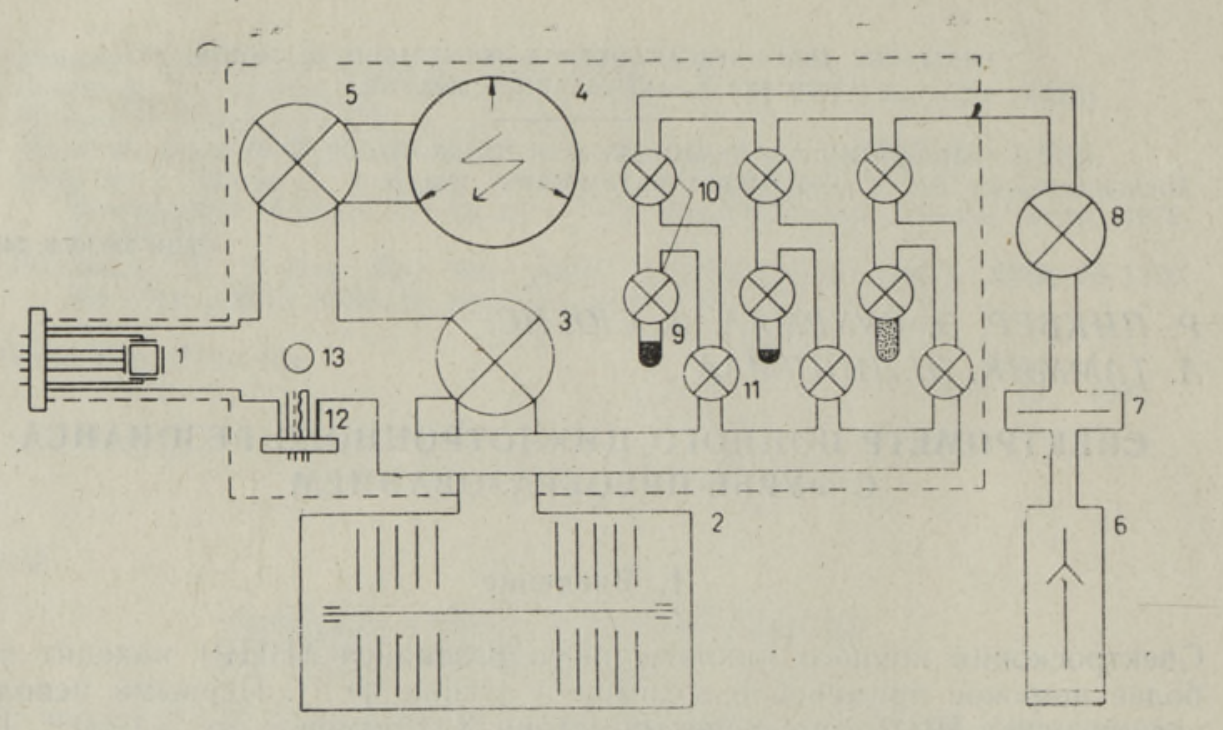

Рис. 1. Вакуумная система.

Основную систему можно дегазировать при максимальной температуре $200^{\circ} \mathrm{C}$, а ячейку - при $400^{\circ} \mathrm{C}$. Та часть вакуумной системы, которая подвергается дегазированию, на рисунке обведена прерывистой линией. Предельный вакуум, который достигается в основной системе после дегазирования, равен $5 \cdot 10^{-9}$ Торр. Вспомогательная вакуумная система откачивается паромасляным диффузионным насосом Н1-C (6) $(100 \mathrm{л} / \mathrm{c})$, в системе имеется также азотная ловушка (7) и основной вентиль (8). Для дегазирования и напуска исследуемых веществ предусмотрены три одинаковых узла. Каждый из них содержит ампулу с исследуемым веществом (9), два вентиля для изолирования вещества от диффузионного насоса (10) и вентиль тонкого регулирования (11). Напуск веществ в основную вакуумную систему происходит через вентили тонкого регулирования модели 959-5106 фирмы «Varian», которые позволяют дозировать газ из ампулы под атмосферным давлением прямо в глубокий вакуум и отделяют эту систему от вспомогательной. Вакуумная система в целом сделана из нержавеющей стали с медными прокладками, и поверхность вентилей и трубок тщательно очищена электрополировкой. Давление в основной системе измеряется ионизационным вакуумметром (12) и емкостным мембранным манометром (13), их диапазоны измерения составляют от $10^{-3}$ до $10^{-11}$ Торр и от 1 до $10^{-5}$ Торр соответственно. Емкостный манометр неселективен к составу газа. Он используется для калибровки ионизационного вакуумметра путем экстраполяции .в более чувствительную область измерения.

\section{3. Ячейка}

Б настоящее время большинство спектрометров ИЦР работает с ячейкой удерживания ионов Мак-Айвера [ $\left.{ }^{7}\right]$. Этот тип ячейки по сравнению с трехсекционной дрейфовой обладает рядом достоинств, которые неоднократно освещались в литературе. Мы остановились на кубической модификации ячейки удерживания ионов Комизароу и Маршалла $\left[{ }^{13}\right]$, поскольку она из-за отсутствия продолговатых дрейфовых орбит позволяет подвергнуть дрейф ионов бо́льшему контролю и получить выигрыш в разрешающей силе в два-четыре раза по сравнению с длинной ячейкой Мак-Айвера. 


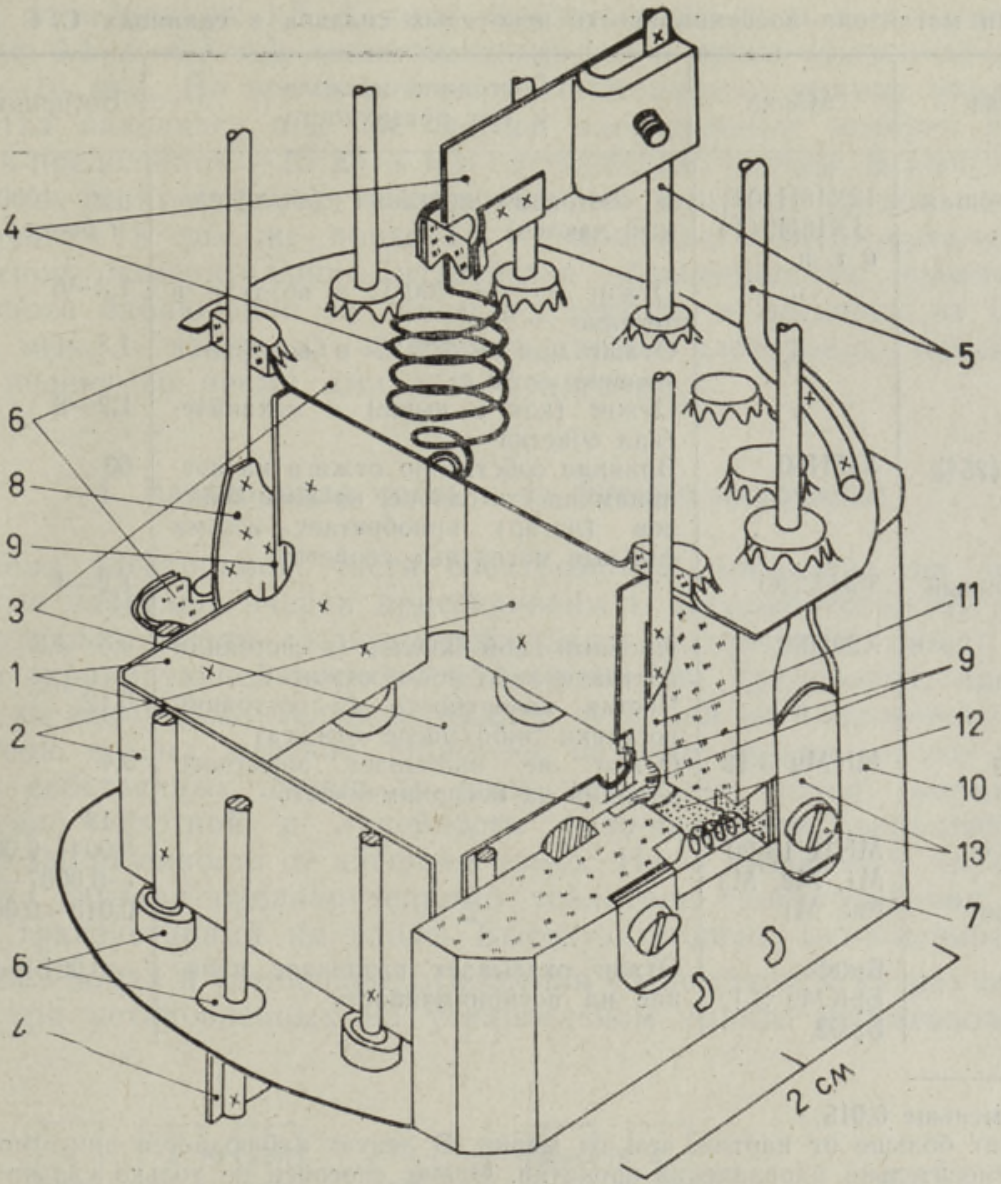

Рис. 2. Кубическая ячейка удерживания ионов.

Построенная нами ячейқа, одна четверть которой условно отрезага, изображена на рис. 2. Пластины удерживания (1), приемника (2) и передатчика (3) скреплены между собой с помощью траверсэ. и пружины (4), выводов (5); корундовых втулок и подпятников $(6)$. В центре пластин удерживания просверлены отверстия, через которые проходит ионизирующий электронный пучок. Для уменьшения проникновения в ячейку электрических полей со стороны катода (7) и коллектора электронов (8) отверстия закрыты проволочными сетками (9). Между отверстиями в катодном блоке (10) и ближайшей к нему пластине удерживания расположена пластинка-носитель с управляющей сеткой (11). Стенки отверстия в катодном блоке покрыты графитовым слоем (12), имеющим контакт с плюсовым выводом катода. Это способствует формированию электронного пучка. Катод закреплен в углублении катодного блока клеммами (13).

При выборе материала для металлических частей ячейки, в первую очередь пластин, мы остановились на нихроме (лента толщиной 0,3 мм марки Х20H80) из-за его низкой магнитной восприимчивости (см. таблицу) и относительно высокой химической устойчивости. Траверсы, пружина и выводы изготовлены из нихрома той же марки, кроме выводов катода, которые для достижения малого электрического сопротивления изготовлены из нейзильбера. Катод сделан из вольфрамовой проволоки марки BA1 группы Г диаметром 100 мкм. Выбором 


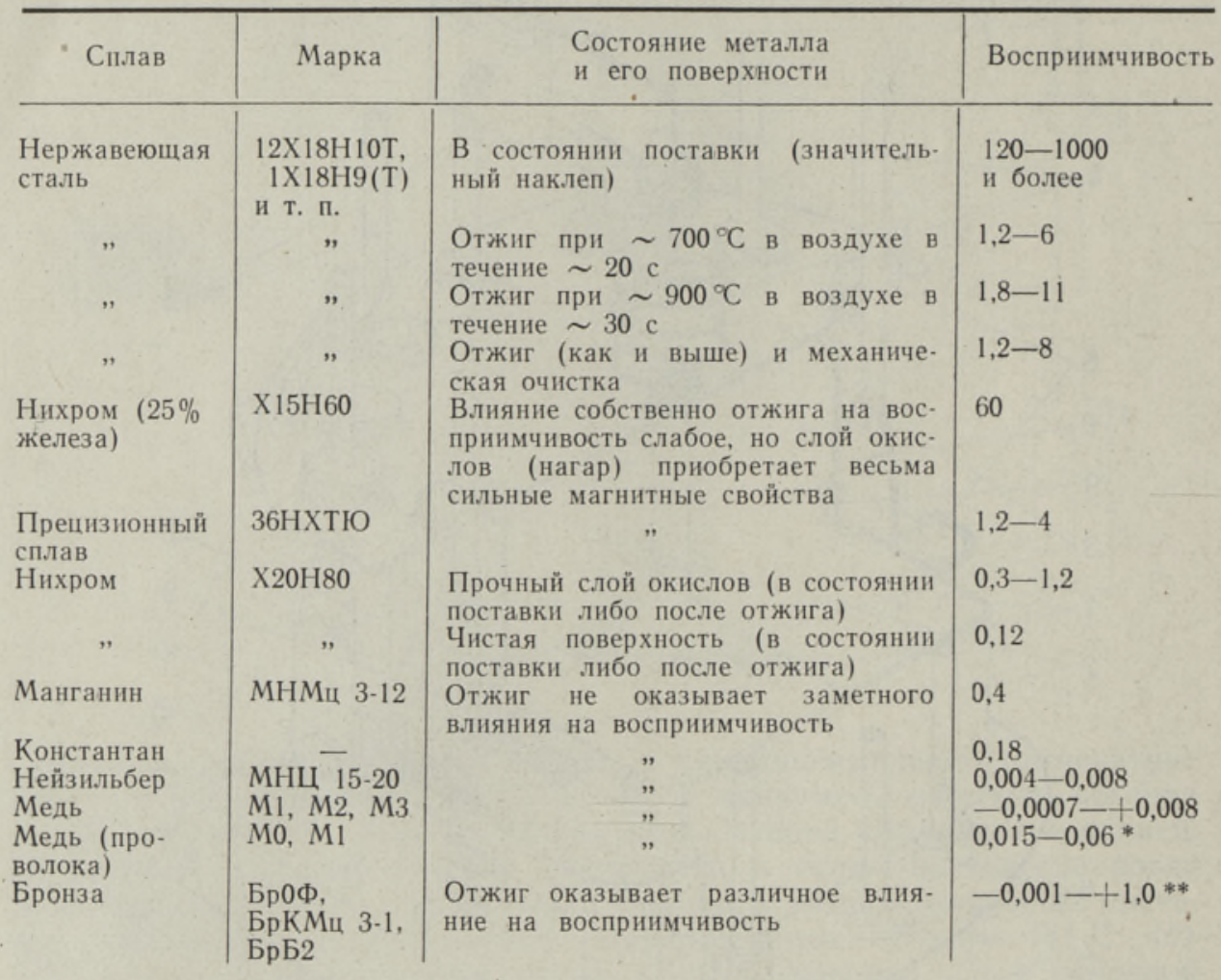

* Редко меньше 0,015 .

** Зависит больше от партии, чем от марки. В лентах наблюдается анизотропия до 10 раз относительно направления прокатки. Отжиг способен не только сильно уменьшать восприимчивость (до 150 раз, на 1,0), но и слабо увеличивать ее (на 0,01 ).

партий проволоки нам удалось получить хорошую стабильность ионизирующего тока. Сетки сделаны из параллельных вольфрамовых проволок диаметром 50 мкм.

Для уменьшения газовыделения ячейки дегазацию желательно проводить при высокой температуре. Неорганические электроизоляционные материалы нашей конструкции позволяли нагревать ячейку до $400{ }^{\circ} \mathrm{C}$. Катодный блок изготовлен из поддающейся механической обработке стеклокерамики «Макор», а остальные готовые изоляторы втулки ВКЦ $30120 \times 1,5$ и подпятники ПКК $2,5 \times 0,25-$ из корунда. Высокочастотные потери этих материалов очень малы.

Изображенные на рис. 2 верхняя и нижняя пластины (3) служат электродами для возбуждения ионов, пара боковых пластин (2) соединена с предварительным усилителем напряжения сигнала ионов. Во время работы с положительными ионами на пластины удерживания (1) подается регулируемое положительное напряжение от 0 до 2 В, а на остальные пластины - отрицательное напряжение от 0 до -2 В. Для удерживания отрицательных ионов нужно менять полярность напряжений на всех шести пла̇стинах. Регулирование этих напряжений осуществляется попарно, так что одним потенциометром можно изменить среднее напряжение на определенной паре пластин, а другим только их разность. Для тушения ионов на одну пластину передатчика подается положительный импульс с амплитудой 10 В и длительностью от 0,2 до 2 мс. 
При токе накала 1,5 А сила эмиссионного тока составляет примерно от 0,1 до 0,3 мА, максимальный ток в пучке обычно не превышает 5-10 мкA. Во время работы в стационарном режиме управляющая сетка находится под постоянным напряжением, которое регулируется в пределах от -15 до +4 В относительно катода. В импульсном режиме на сетку подается положительный импульс, уровни которого регулируются в тех же пределах. С помощью электрометрического импульсного измерительного устройства обеспечивается возможность постоянного наблюдения за током коллектора в пределах от 0,1 нА до 100 мкА, а также за величиной заряда электронов, прошедших сквозь ячейку во время импульса ионизации.

\section{4. Электронная часть и ее функционирование}

Блок-схема электронной части спектрометра приведена на рис. 3 . Приемные пластины ячейки присоединены к предварительному усилителю, который вместе со вспомогательным мостом (см. ниже) находится в экранирующей коробке вблизи ячейки. Требования, предъявляемые ко всему усилительному тракту от входа до аналогового перемножителя, весьма жесткие. Наиболее важные из них - это малый уровень собственных шумов во всем диапазоне частот, постоянство амплитудно-частотной и линейность фазо-частотной характернстик, а также защищенность от внешних помех. Из-за емкостного характера источника сигнала предварительный усилитель сконструирован с полевыми транзисторами на входе. Высокую степень защищенности от синфазных помех й увеличение отношения сигнал/шум в $\sqrt{2}$ раз обеспечивают три установленных на усилительном тракте широкополосных

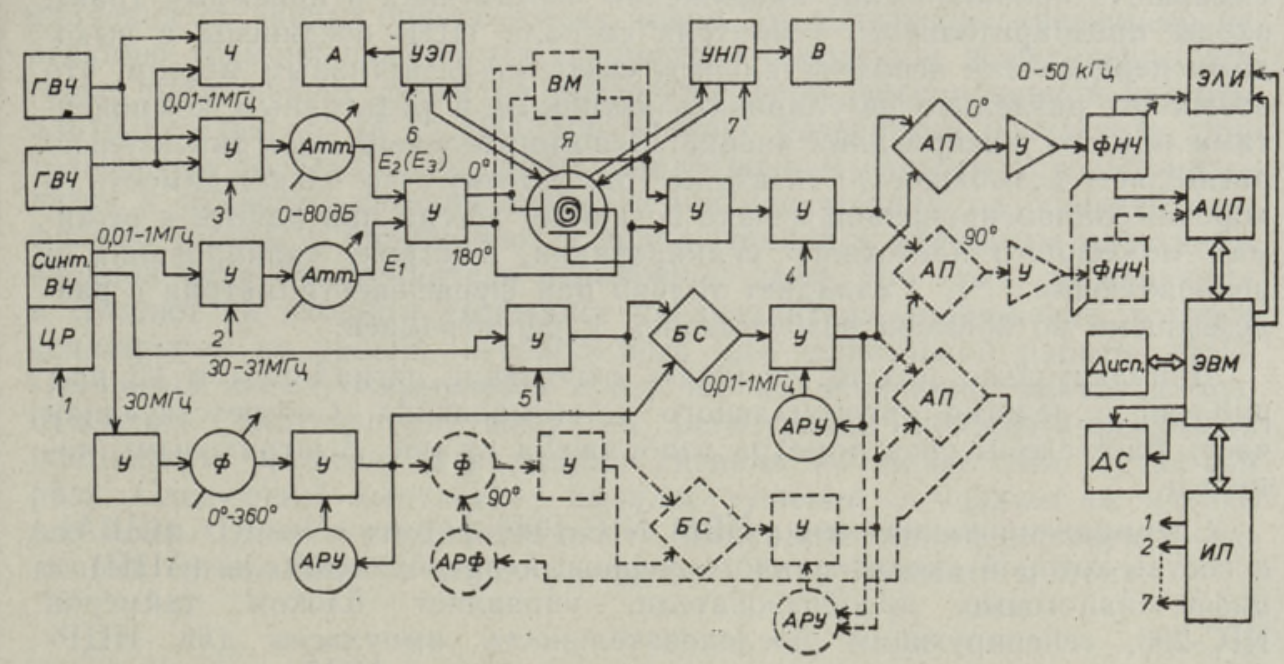

Рис. 3. Блок-схема спектрометра ИЦР: Я - измерительная ячейка; ВМ - вспомогательный мост; УЭП - блок питания электронной пушки, управления электронным пучком и измерения его параметров; УНП - блок управления напряжениями пластин; ГВЧ - генераторы ВЧ; Синт. ВЧ - синтезатор ВЧ; ЦР - блок цифровой развертки; У - широкополосные (в квадратах) и операционные (в треугольниках) усилители; Ч, А, В - цифровые частотомер, амперметр и вольтметр; Атт. - аттенюаторы; Ф фазовращатели; АРУ, АРФ - цепи автоматической регулировки уровня и фазы $\left(90^{\circ}\right)$; БС - балансные смесители ВЧ; АП - аналоговые перемножители; ФНЧ - активные фильтры нижних частот (Баттерворта); ЭЛИ - электроннолучевой индикатор; АЦП аналого-цифровой преобразователь; ЭВМ - мини-ЭВM NIC-1086; Дисп. - дисплей с клавиатурой, ДС - двухкоординатный самописец; ИП - импульсный программатор. 
дифференциальных интегральных усилителя типа 733, способных к электронному регулированию усиления. Усиление до аналогового перемножителя переключается степенями $\left(X^{2}\right)$ в пределах от $10^{3}$ до $4 \cdot 10^{5}$.

Для выполнения требований к амплитудно- и фазо-частотным характеристикам верхний предел полосы пропускания усилителя должен в несколько раз превышать максимальную рабочую частоту. Между усилительными каскадами помещены два интегральных аналоговых МДП-коммутатора, на которые возложено импульсное управление приемным трактом. После усиления сигнал поступает на аналоговый перемножитель типа MC 1495, где и преобразуется в сканирующем режиме в «нулевую» частоту, а при работе с фурье-преобразованием происходит частотный сдвиг вниз, в полосу рабочих частот аналогоцифрового преобразователя. Опорное напряжение синтезируется из напряжений с частотами 30 МГц и 30-31 МГц, которые вырабатываются в декадном генераторе, от которого поступает напряжение и для возбуждения ионов с частотой $0,01-1$ МГц. Такой способ синтеза опорного напряжения позволяет осуществлять частотнонезависимую регулировку его фазы в пределах $0-360^{\circ}$ несложными схемотехническими решениями. Декадный генератор дополнен цифровым блоком развертки частоты.

Канал передатчика состоит из двух предварительных усилителей c аналоговыми коммутаторами и аттенюаторами $0-80$ дБ и двух симметричных оконечных усилителей с прецизионно-симметричными выходами $2 \times 1$ В и $2 \times 10$ В. Приемные пластины ячейки уже конструктивно сбалансированы $(\sim 1: 10)$ относительно передающих пластин так, что вместе с симметричным выходом передатчика образуют главный мост. Такое грубое сбалансирование доведено до $\sim 1: 100$ путем сгибания четырех лепестков в ячейке. Чтобы еще уменьшить проникновение напряжения передатчика в приемный тракт, входы предварительного усилителя сигнала ИЦР соединены с выходами передатчика вспомогательным емкостно-резистивным мостом, что позволяет раздельно регулировать активным и реактивным компонентами при сбалансировании ячейки. Вспомогательный мост значительно расширяет возможности спектрометра, потому что необходимость в хорошо сбалансированной ячейке возникает всегда при работе в режимах медленного частотного сканирования, быстрого сканирования и деконволюции $\left[{ }^{14}\right]$, а отпадает только при фурье-спектрометрии с разделенными во времени возбуждением и регистрацией.

Дополнительно можно увеличить отношение сигнал/шум в $\sqrt{2}$ раз, работая в режиме ортогонального детектирования. Соответствующая часть блок-схемы спектрометра изображена на рис. 3 штриховыми линиями.

Специализированная мини-ЭBM NIC-1086 фирмы «Nicolet» (США), в состав которой входят аналого-цифровый преобразователь (АЦП) и цифро-аналоговые преобразователи, управляет блоком таймеров NIC-293, генерирующим последовательность импульсов для ИЦРэксперимента (см. ниже), дискретизирует сигнал ИЦР и записывает его в память ӘВМ, изображает содержимое памяти на экране электроннолучевого нндикатора и осуществляет быстрое преобразование Фурье (БПФ) параллельно с другими приемами цифровой обработки сигнала ИЦР во временной - или частотной области. Для всех целей применялись программы, созданные для ЯМР-спектрометрии.

На рис. 4 изображен один цикл последовательности импульсов ИЦР-эксперимента с БПФ (или 'эксперимента для регистрации кинетических кривых без БПФ). Первый импульс длительностью около 10 мс открывает электронную пушку ячейки и в течение этого про- 


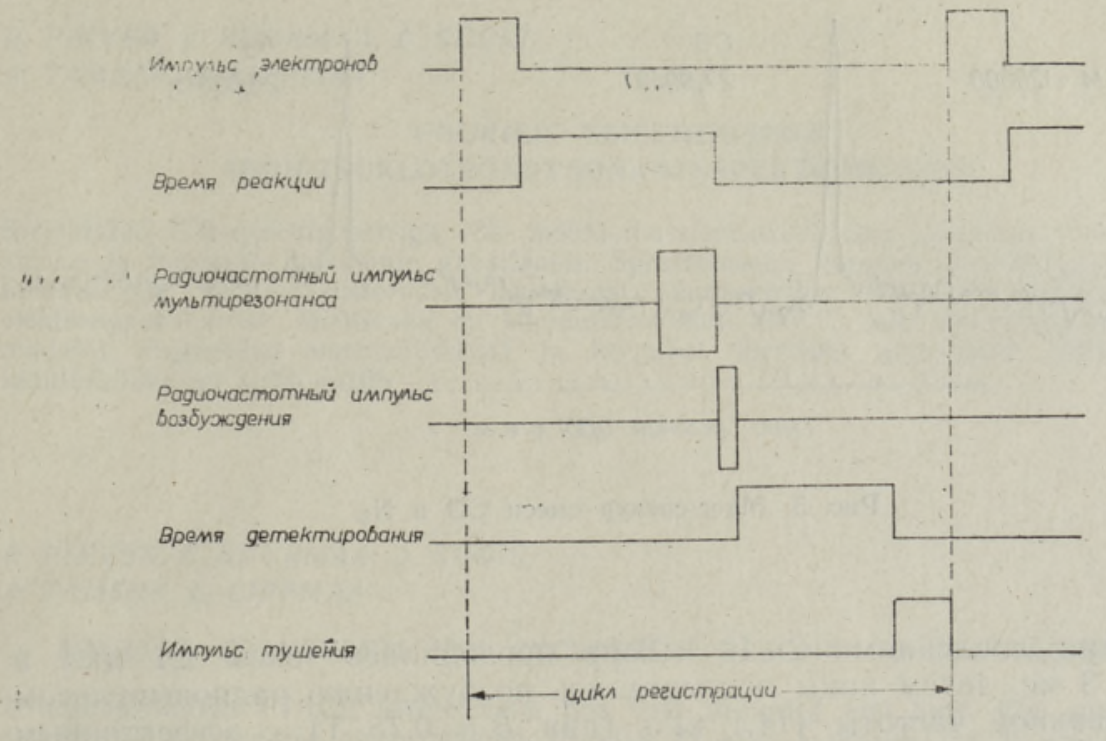

Рис. 4. Цикл работы ячейки.

межутка времени определенное количество молекул газа, заполняющих ячейку, ионизируется электронным ударом. В течение следующего интервала времени образовавшиеся ионы реагируют с нейтральным газом. Время реакции задается обычно в пределах от нуля до нескольких секунд. При мультирезонансном эксперименте во время реакции включается соответствующим импульсом другой канал передатчика для удаления из ячейки определенных ионов. По истечении отведенного на реакцию времени включается следующим импульсом возбуждение, которое представляет собой радиоимпульс либо фиксированной частоты длительностью от 10 до 1000 мкс, либо с разверткой по частоте длительностью порядка 1 мс. Ионы, циклотронные частоты которых находятся в пределах спектра возбуждения, ускоряются на бо́льшие синфазные орбиты и индуцируют в подключенной к приемным пластинам входной цепи предусилителя переменные токи. Эти токи суммируются и создают на входном импедансе предусилителя напряжение, которое усиливается до уровня, необходимого для нормальной работы АЦП. Приемный канал открывается сразу же по окончании импульса возбуждения. 'Длительность импульса регистрации должна превышать постоянную времени затухающего сигнала не менее чем в два-три раза. Следующий импульс - импульс тушения - удаляет из ячейки все ионы. Цикл последовательности импульсов можно повторить, накопляя сигнал ИЦР с целью увеличения его отношения к шуму.

\section{5. Результаты}

Полуторагодичный опыт эксплуатации ИЦР-спектрометра подтвердил его эффективность при исследовании ионно-молекулярных реакций, в частности, реакций переноса протона $\left[{ }^{15}\right]$. Более того, спектрометр способен работать в качестве аналитического масс-спектрометра с высоким разрешением для положительных и отрицательных ионов. Для примера приведем масс-спектр положительных ионов СО и $\mathrm{N}_{2}$, разница масс которых составляет 0,01124 а. е. м. (рис. 5). Процедура регистрации спектра была следующей: ионизация смеси газов с пар- 


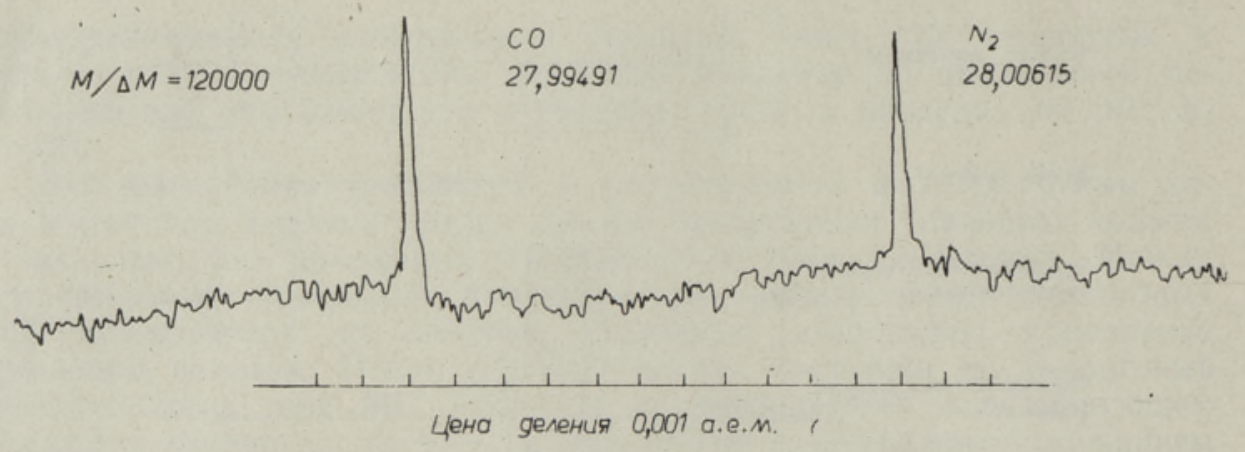

Рис. 5. Масс-спектр смеси СО и $\mathrm{N}_{2}$.

циальными давлениями $2 \cdot 10^{-8}$ Торр проводилась током 2,1 мкА в течение 3 мс, затем ионы подвергались возбуждению радиоимпульсом фиксированной частоты 414,1 кГц (при $B=0,75$ Т) с эффективным значением напряжения $2 \times 280$ мВ и длительностью 200 мкс. Далее следовали дискретизация сигнала с частотой выборок 800 Гц и одновременная запись его в блок памяти объемом $2 \mathrm{~K}$ слов по 20 бит. Цикл завершал гасящий импульс длительностью 10 мс. После 16 накоплений в теqение 5 с был получен ИЦР-спектр поглощения в частотной области путем фурье-преобразования записанного во временной области сигнала ИЦР.

\section{Л И ТЕ Р А Т У Р А}

1. Леман T., Берси М. Спектроскопия ионного циклотронного резонанса. М., «Мир», 1980.

2. Кабачник М. Н. Успехи химии, 48, вып. 9, 1523-1546 (1979).

3. McIver, R. T. Jr. Int. Lab., 17-27 (1981).

4. Wilkins, C. L., Gross, M. L. Anal. Chem., 53, № 14, 1661A-1676A (1981).

5. Sommer, H., Thomas, H. A., Hipple, J. A. Phys. Rev., 82, № 5, 697-702 (1951).

6. Baldeschwieler, J. D. Science, 159, № 3812, 263-273 (1968).

7. Mclver, R. T. Jr. Rev. Sci. Instrum., 41, № 4, 555-558 (1970).

8. Comisarow, M. B., Marshall, A. G. Chem. Phys. Lett., 25, № 2, 282-283 (1974).

9. Comisarow, M. B., Marshall, A. G. J. Chem. Phys., 62, № 1, 293-295 (1975).

10. Mclver, R. T. Jr. In: Ion Cyclotron Resonance Spectrometry (Hartman H., Wanczek K.-P., Eds.). Springer-Verlag, Berlin-Heidelberg-New York, 1978, p. $97-135$.

11. Alleman, M., Kellerhals, H. P., Wanczek, K.-P. Chem. Phys. Lett., 75, № 2, 328331 (1980).

12. Коппель И. А., Пиквер Р. И., Сюгис А. Ю., Суурмаа Э. Р., Липпмаа Э. Т. Реакц. способн. орг. соед., 18, вып. 1 (65), 5-20 (1981).

13. Comisarow, M. B. Int. J. Mass Spectrom. Ion Phys., 37, № 2, 251-257 (1981).

14. Marshall, A. G. Chem. Phys. Lett., 63, № 3, 515-518 (1979).

15. Коппель И. А., Пиквер Р. И., Сюгис А. Ю., Суурмаа Э. Р., Липпмаа Э. Т. Докл. AH CCCP, 265, № 3, 650-653 (1982).

Ннститут химической и биологической физики Академии наук Эстонской ССР
Поступила в редакцию 19 августа 1982 


\section{FOURIER' TEISENDUSEGA IOON-TSUKLOTRONRESONANTSSPEKTROMEETER}

Kirjeldatud ITR-spektromeetriga vōib mõōta massispektreid ning keemiliste reaktsioonide kiiruse ja tasakaalu konstante gaasifaasis. Spektromeeter koosneb elektromagnetist koos toiteallikaga, vaakuumsüsteemist, kuubilisest sümmeetrilise lülitusega mōôterakust ja elektronaparatuurist. Mõōterakk on kuumutatav kuni $400^{\circ} \mathrm{C}$, selle materjalid on valitud madalat magnetilist vastuvõtlikkust ja keemilist inertsust arvestades. Spektromeetri lahutusvõime on kuni $\sim 10^{5}$.

\section{R. PIKVER, E. SUURMAA, A. SUGIS,}

A. TAMMIK, E. LIPPMAA

\section{FOURIER TRANSFORM ION CYCLOTRON RESONANCE SPECTROMETER}

A high-resolution FT-ICR spectrometer has been designed and built. The spectrometer consists of a large-gap electromagnet $(B=0.8 \mathrm{~T})$ with a precise $\left(10^{-6}\right)$ power supply, a vacuum system, an ICR cell, electronic units, and a minicomputer with peripherals. The vacuum syștem (Fig. 1) combines triode ion and turbomolecular pumps in the main line, and a diffusion pump in the sample line. The ultra-high $\left(5 \cdot 10^{-9}\right.$ Torr $)$ vacuum system is all-metal and bakeable. A cubic trapped-ion ICR cell (Fig. 2) of organic-free design is made of carefully selected materials and is bakeable up to $400^{\circ} \mathrm{C}$. Magnetic volume susceptibility of various metal alloys has been measured (see Table) and nichrome $80-20$ was chosen for the ICR cell. Insulating materials used are machineable glass-ceramic and sapphire bearings. Block diagram of the electronics is depicted in Fig. 3. The precise split-phase transmitter, the fully symmetric cell and the preamplifier are electrically balanced and form a broadband bridge. For increased experimental flexibility, the inherent, but coarse balance is further increased by bendable «paddles» mounted in the vicinity of the cell plates and, still further, by an optional auxiliary two-component bridge. In the FT mode, the excitation radiofrequency pulse may be of fixed frequency or with a rather fast scan («chirp» pulse). The latter is accomplished by a frequency synthesizer with digital frequency stepping with the rate up to $10^{5} \mathrm{steps} / \mathrm{s}$. With the same frequencv synthesizer, a rapid scan technique exploiting cross-correlation computation and the usual slow, yet frequency scan technique (no spectral computation, only accumulation) are equallv possible. A reference channel (shown in the lower part of Fig. 3) operates at a higher frequency to achieve frequency-independent but variable phase shift and to get a $90^{\circ}$ reference voltage for an optional quadrature detection channel (shown in broken lines). The prevalent operating mode of a trapped-ion cell is cyclic (Fig. 4), including creation of the ions by the electron beam, optional time for chemical reactions, double (multi) resonance irradiation during some portion of that time, excitation of ions, detection of the ICR signal, and quench. The quench-off regime is possible for ion collection with pulsed or even continuous electron beam. The mass resolution is limited to $\sim 1 \cdot 10^{5}$ by the rather low magnetic field strength. A sample spectrum of the $\mathrm{CO}-\mathrm{N}_{2}$ doublet registered in the FT mode with the cell cycle time of $0.3 \mathrm{~s}$ and accumulated 16 times, is presented in Fig. 5. 